\section{African Botany}

A Vegetition Map of Africa in colour, with accompanying explanatory notes by $\mathbf{R}$. W. J. Keay, and with a French translation by A. Aubréville, has been published on behalf of l'Association pour l'Étude 'Taxonomique de la Flore d'Afrique Tropieale, with the assistance of Unesco (Oxford University Press (1959), price 15s. in the United Kingdom only). The vegetation concerned is that which occurs south of the Tropic of Cancer. The author explains that the aim of the map is to show the vegetation as it is to-day and not the presumed climax types. $\mathrm{He}$ points out that the boundaries between the zones are seldom precise on the ground although, in the interests of clarity, they are thus represented on the map. The name selected for any particular zone relates to the most widespread natural or semi-natural type of vegetation found within it. Other necessary clarifying observations are also indicated.

\section{'Parsnip' Dermatitis}

UNDER this title B. J. Youngman has given an interesting account of various blisters and rashes caused by certain umbelliferous species, in particular those of Heracleum and Pastinaca (Kew Bulletin, 3, $387 ; 1958$ ). In one instance, boys who had been playing with the giant species Heracleum mantegazzianum, using the stout stems as swords and telescopes, developed such severe red rashes and, later, blisters, as to require hospital treatment. This species of 'cow parsnip', which may grow to a hoight of $12 \mathrm{ft}$. with hollow stems 4 in. in diameter, is a native of the Caucasus. Originally introduced into Britain as a garden plant, it has now become naturalized in waste places, along rivers, etc. The author also discusses the edible, acrid, and vesicant properties of other species of Heracleum and of Pastinaca, to which the domestic parsnip $(P$. sativa $)$ belongs, and cites evidence of more or less severe dermatitis effects which have been traced to them. She also recalls that some of the Umbelliferæ have not merely acrid and scalding juices or ingredients but are virulently poisonous, for example, hemlock. So far the toxic principles present in species of Heracleum, Pastinaca and other umbelliferous plants have not been isolated or identified.

\section{The Mammals of Banff National Park, Alberta}

IN 1885, an area of 10 square miles around the newly discovered hot springs in the Bow Valley of the Alberta Rockies was designated as Rocky Mountain National Park. This was Canada's first national park. Since that date the park boundaries have been altered several times, and the name has been changed to Banff National Park. The present area of the park is 2,585 square miles. It stretches for 210 miles along the eastern flank of the Rocky Mountain from latitude $50^{\circ} 45^{\prime}$ to $52^{\circ} 45^{\prime} \mathrm{N}$. The western boundary is the continental divide. Six main mountain ranges, the axes of which lie north. west-south-east, are contained in the park. A survey of the mammals of the extensive area has been made by $\mathrm{A}$. W. Banfield, who describes 17 species in tho Cordilleran fauna, 11 in the Boreal fauna, 7 in the Prairie fauna, 1 species in the Tundra fauna, and 18 of uneertain affinities (Nat. Mus. Canada, Bull. 159, Biol. Ser., 57).

\section{The Ophitron}

The Generat, Eurectric Co., Ltd., announces that a compact microwave-generatior embodying a new focusing principle has been developed at its research laboratories. The valve is an electrostatically focused backward-wave oscillator which has been named the 'Ophitron', after the Greek ophis, a serpent, the word being suggested by the undulating path of the electron stream flowing along the structure. The most striking advantages of the new oscillator are its small size ( 6 in. long and $\frac{3}{4}$ in. diameter) and low weight ( 7 oz.), and in addition the 'Ophitron' system has been designed to be simple to construct and to operate. A single stamped-out periodic structure and two flat focusing plates form the propagating path for the radio-frequency wave, and set up the periodic electrostatic field which foeuses the electron beam. The system has the fundamental advantage that the crests of the undulating electron beam are brought into the region of maximum radio-frequency field. This feature gives good coupling between beam and wave, and leads to greater bandwidth than is obtained with the equivalent magnetically focused backward-wave oscillator. 'The present 'Ophitron' tunes electronically over at least a 40 per cent band in the $10,000 \mathrm{Mc}$./s. region. A range of such valves is envisaged, covering most important centimetre wave-length bands. It is expected that the noise performance will be better than that of magnetically focused backward-wave oscillators due to the ion drainage from the electron beam inherent in the focusing method.

\section{Non-Oxide Glasses}

ARSENIC trisulphide glass is well known as a useful material in the construction of optical parts trans. mitting in the infra-red. It suffers from a very low softening temperature compared with the normal type of oxide glass, and so far there is very little promise of harder glasses being prepared with sulphur or selenium as the anion. Some of these glasses are semiconductors of high resistivity, greater than $10^{8} \mathrm{ohm} / \mathrm{cm}$. $/ \mathrm{cm}^{2}$. The Bell Telephone Laboratories have just announced an ingenious application of glasses in this family which puts to practical use the low-softening point, the property which is undesired in the other present uses. Glasses composed of varying proportions of sulphur or selenium with arsenic and thallium become very fluid at temperatures between $125^{\circ} \mathrm{C}$. and $350^{\circ} \mathrm{C}$. In this temperature-range the viscosities of the various glasses approximate to that of castor oil at room temperature. These materials have been found to be eminently suitable for coating small electronic devices by dipping into the castor oil-like liquid. At room temperature the materials are typically glass-like solids inert chemically to most reagents except concentrated alkalis. Several compositions are said to resist oxidation in air to above $250^{\circ} \mathrm{C}$. Initial experiments in coating semiconductor devices have shown considerable promise.

\section{Joseph P. Kennedy, Jr. Memorial Foundation}

A GIFT of one million dollars has been made by the Joseph P. Kennedy, Jr. Memorial Foundation for the establishment of the Joseph P. Kennedy, Jr. Laboratories for research on mental retardation, at the Massachusetts General Hospital. One half of this generous gift will be spent on the construction of these Laboratories and the other half will serve as an endowment to provide continuing operating funds. This is the first of the endowed scientific researchships planned under the 1961 programme in observance of the 150th anniversary of the Massachusetts General Hospital. 